\title{
ESPECIFICIDADES SOBRE FORMAÇÃO DE PROFESSORES NO ENCONTRO BRASILEIRO DE ENSINO SUPERIOR A DISTÂNCIA (ESUD)
}

\author{
SPECIFICITIES IN TEACHERS TRAINING PROCESS AT THE BRAZILIAN \\ MEETING OF DISTANCE HIGHER EDUCATION (ESUD)

\section{ESPECIFICIDADES FORMACIÓN DE PROFESORES EN EL ENCUENTRO BRASILEÑO SUPERIOR A DISTANCIA (ESUD)}

\author{
Ana Laura Salcedo de Medeiros ${ }^{1}$, Maria do Carmo Galiazzi ${ }^{2}$
}

\begin{abstract}
RESUMO
O Encontro Brasileiro de Educação Superior a Distância (ESUD) é um evento de uma comunidade científica que apresenta pesquisas na modalidade da Educação a Distância $(\mathrm{EaD})$, o que inclui, entre outros, pesquisas sobre a formação de professores. Investigaram-se os autores e as obras referenciados de 131 artigos enviados para as edições do evento de 2008 até 2015. O objetivo deste levantamento foi compreender as especificidades da EaD tendo por base as obras mais referenciadas nos trabalhos do ESUD que tratam de pesquisas sobre a formação de professores na EaD. Buscou-se compreender, a partir da pergunta fenomenológica: "O que é isso que se mostra de especificidade na Educação online nos autores mais referenciados em artigos sobre formação de professores do Encontro Brasileiro de Educação Superior a Distância (ESUD)?”. Os interlocutores teóricos mais referenciados foram: José Manuel Moran, Maria Luiza Belloni, Pierre Lévy, José Armando Valente e Maria Elizabeth Bianconcini de Almeida. Encontraram-se as seguintes especificidades da Educação online nas obras dos autores estudados; à interatividade e à comunicação no ambiente virtual; à compreensão sobre tecnologia intelectual; e, ao tempo e espaço na Educação online.
\end{abstract}

PALAVRAS-CHAVE: Formação de Professores. Conceitos Estruturadores. Educação online.

\section{ABSTRACT}

The Brazilian Meeting of Distance Higher Education (ESUD) is an event of a scientific community in which Distance Learning $(\mathrm{EaD})$ researches are presented and it covers researches in teacher training processes. The most cited works of one hundred and thirty-one articles of this event from 2008 to 2015 were investigated. The goal of this analysis is to understand the specificities of $\mathrm{EaD}$ on the most referenced works at ESUD regarding teacher training processes in Distance Learning. We shall try to understand the phenomenological question: "What is it that particularly shows itself in those referenced works of ESUD about teachers training in the online context?". Regarding theoretical interlocutors, the most cited ones were José Manuel Moran, Maria Luiza Belloni, Pierre Lévy, José Armando Valente and Maria Elizabeth Bianconcini de Almeida. Specific aspects in online Education were found in the

\footnotetext{
${ }^{1}$ Doutoranda do Programa de Pós-Graduação de Educação em Ciências, Química dada Vida e Saúde (PPGEC) da Universidade Federal do Rio Grande (FURG),

${ }^{2}$ Orientadora do Programa de Pós-Graduação do PPGEC da FURG.
}

\begin{tabular}{l|c|c|c|}
\hline Rev. Ciências Humanas & Frederico Westphalen, RS & Pg. 52 - 67 & mai./ago. 2018 \\
\hline
\end{tabular}

\begin{tabular}{l|l} 
Recebido em: 09/07/2018 & Aceito em: 21/09/2018
\end{tabular}




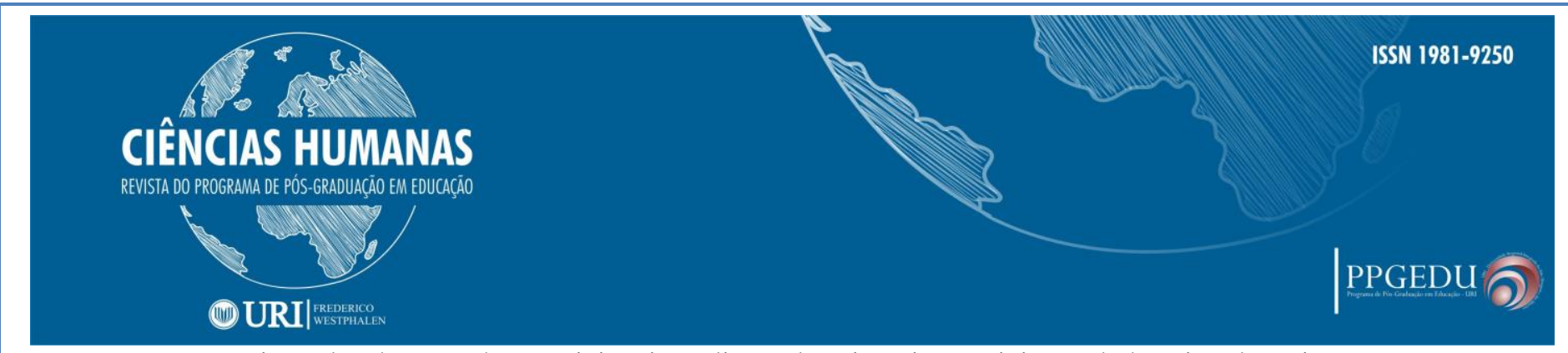

categories related to teachers training in online Education; interactivity and the virtual environment interaction; and comprehension of time and space and intellectual technology in online Education.

KEYWORDS: Teachers Training. Specific concepts. Online Education

\section{RESUMEN}

El Encuentro Brasileño de Educación Superior a Distancia (ESUD) es un evento de una comunidad científica que presenta investigaciones en la modalidad de la Educación a Distancia (EaD) lo que incluye, entre otros, investigaciones sobre la formación de profesores. Se investigó a los autores referenciados de ciento treinta y un artículos enviados para las ediciones del evento de 2008 hasta 2015. El objetivo de este levantamiento fue comprender las especificidades de la $\mathrm{EaD}$ en las obras más referenciadas en los trabajos del ESUD que tratan de investigaciones sobre la formación de profesores en la EaD. Se buscó comprender a partir de la pregunta fenomenológica: "¿Qué se muestra de específico sobre formación de profesores en el contexto online de los autores más referenciados en los artículos del Encuentro Brasileño de Educación Superior a Distancia (ESUD)?". Los interlocutores teóricos más referenciados fueron: José Manuel Moran, Maria Luiza Belloni, Pierre Lévy, José Armando Valente y Maria Elizabeth Bianconcini de Almeida. Se han encontrado aspectos específicos de la Educación online en las categorías relativas a la formación de profesores en la Educación online; la interacción y la comunicación en el entorno virtual; la comprensión sobre tecnología intelectual y el tiempo y espaço en la educación online.

PALABRAS CLAVE: Formación de profesores. Conceptos Específicos. Educación online.

\section{A PESQUISA}

Neste artigo pretende-se apresentar especificidades da Educação online para a formação de professores no contexto online. ${ }^{3}$ Entende-se especificidade como a qualidade particular. Neste caso, como uma qualidade particular da Educação online que foi elaborada a partir dos argumentos retirados das obras mais referenciadas nos artigos do Encontro Brasileiro de Ensino Superior a Distância (ESUD) que trataram da formação de professores. A questão central do estudo é "O que é isso que se mostra de especificidade para a formação de professores no contexto online nas obras mais referenciadas nos artigos que tratam da formação de professores na EaD do Encontro Brasileiro de Educação Superior a Distância (ESUD)?"

Analisar os trabalhos publicados sobre a formação de professores na Educação online neste evento, possibilitou-nos construir interrelações sobre processos formativos de docentes no âmbito da modalidade a distância. Este texto apresenta, inicialmente, a metodologia de pesquisa, seguido da descrição das especificidades a formação de professores para o contexto online: a interação e a comunicação, o tempo e espaço e a tecnologia intelectual na Educação online.

\footnotetext{
${ }^{3}$ Assumimos Educação online e ampliamos para a formação no sentido de Silva (2003, p. 11): "é o fenômeno da cibercultura, isto é, o conjunto de técnicas, práticas, atitudes, modos de pensamento e valores que se desenvolvem no ciberespaço".
} 


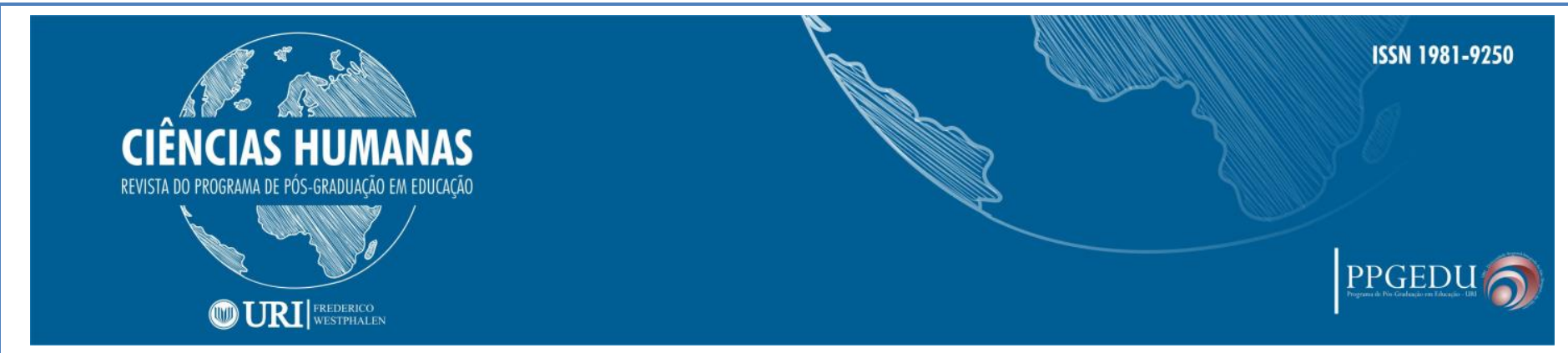

\section{METODOLOGIA}

Para o estabelecimento do corpus desta pesquisa foi reunida a produção científica publicada nos anais dos eventos anuais do ESUD ${ }^{4}$, disponibilizada no site da UniRede. A UniRede é a entidade responsável pela organização do ESUD, e consiste, desde 2006, em um consórcio interuniversitário, composto por Instituições de Ensino Superior Públicas (IESP) com o objetivo de garantir a qualidade acadêmica dos programas de EaD (UNIREDE, 2013).

O ESUD iniciou em 2002. Teve interrupção para novamente acontecer a partir de 2008. Foram selecionados 131 resumos de artigos dos anais que indicaram as referenciais mais citadas do evento de 2008 até $2015^{5}$. Para realizar este levantamento, primeiro foram selecionados trabalhos que no título, resumo ou palavras-chave apresentassem a expressão formação de professores. Foram selecionados: seis artigos, em 2008; 15, em 2009; 21, em 2010; 22, em 2011; 16, em 2012; 17, em 2013; sete, em 2014; e 27, em 2015. A seguir todos artigos selecionados em "Portable Document Format", em português "Formato Portátil de Documento" (.pdf), foram organizados no programa de software Atlas $T I^{6}$. Essa ferramenta, a partir da codificação atribuída aos títulos e palavras-chave, auxiliou na organização das informações, possibilitando a visualização dos resumos e dos referenciais teóricos que embasaram os estudos dos artigos em análise.

Os autores e suas obras mais referenciados pela comunidade científica apontados na análise foram: José Manuel Moran, Maria Luiza Belloni, Pierre Lévy, José Armando Valente e Maria Elizabeth Bianconcini de Almeida, como mostrado no gráfico a seguir:

\footnotetext{
${ }^{4}$ Não tivemos acesso à produção de 2002 pois os anais desse evento se encontram em forma de programas de criação, edição e exibição de apresentações gráficas, o que impossibilitou o acesso aos resumos daquele ano. $\mathrm{O}$ evento conta com onze edições.

${ }^{5}$ Esta pesquisa faz parte de um doutoramento iniciado em 2015, e esse foi o ano limite desse levantamento inicial.

${ }^{6}<$ http://www.software.com.br/p/atlas-ti>.
} 
Gráfico 1 - Autores referenciados na Formação de professores no contexto da Educação online no ESUD

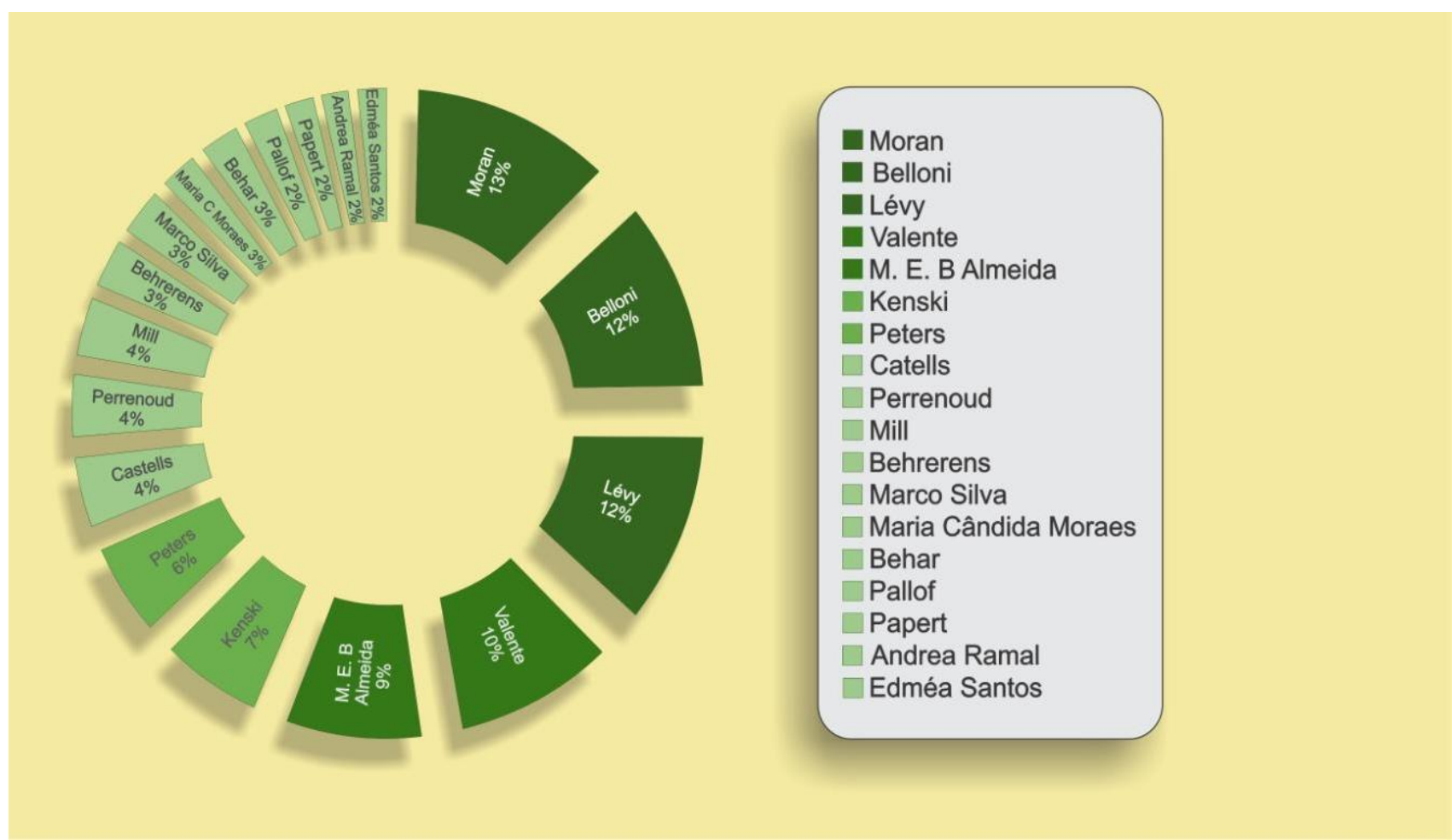

Fonte: Acervo das autoras, 2016.

O gráfico 1 mostra que mais da metade das citações nos artigos (56\%) são dos autores: José Manuel Moran (13\%), Maria Luiza Belloni (12\%), Pierre Lévy (12\%), José Armando Valente (10\%) e Maria Elizabeth Bianconcini de Almeida (9\%), ou seja, dos 19 autores mais citados nestes artigos, 56\% das interlocuções teóricas se concentram em cinco autores. Este é um indicativo de que as teorias e os princípios difundidos por estes interlocutores consolidam o embasamento teórico dessa comunidade no ESUD. As obras mais citadas desses interlocutores teóricos, em ordem crescente de referências, são: Moran (2012), Belloni (2006), Lévy (2008), Valente (2009) e Almeida (2012), as quais estão especificadas no quadro 1.

Destes cinco autores, Pierre Lévy não é brasileiro, nasceu na Tunísia e mora na França, sendo

[...] um reconhecido pesquisador das tecnologias da inteligência e investiga as interações entre informação e sociedade. Mestre em História da Ciência e Ph.D. em Comunicação e Sociologia e Ciências da Informação pela Universidade de Sorbonne, é um dos mais importantes defensores do uso do computador, em especial da internet, para a ampliação e a democratização do conhecimento humano. (FRONTEIRAS DO PENSAMENTO, p.7) 
José Manuel Moran um espanhol, naturalizado brasileiro, professor aposentado da Universidade de São Paulo (USP) de Novas Tecnologias (MORAN, [2002]) e autor de diversos livros relacionados a temática EaD e TIC. Maria Luiza Belloni ${ }^{7}$, professora aposentada da Universidade Federal de Santa Catarina (UFSC), ainda atua no Grupo de Pesquisa Comunic, estuda as inter-relações entre as mídias e os processos educacionais. José Armando Valente ${ }^{8}$, livre Docente pela Universidade Estadual de Campinas (UNICAMP Professor Titular do Departamento de Multimeios, Mídia e Comunicação, Instituto de Artes, e Pesquisador do Núcleo de Informática Aplicada à Educação (NIED) da UNICAMP. Maria Elizabeth Biacocini Almeida ${ }^{9}$, professora associada da Pontifícia Universidade Católica de São Paulo (PUC-SP), atua em Educação e Tecnologias, com pesquisas e publicações sobre currículo e tecnologias, educação a distância, tecnologias e formação de professores, web currículo, cultura digital e educação, narrativa digital.

Quadro 1 - Referências mais citadas na formação de professores no ESUD

\begin{tabular}{|c|c|c|}
\hline Autor & Obra & Referência \\
\hline José Manuel Moran & $\begin{array}{c}\text { Contribuições para } \\
\text { uma pedagogia } \\
\text { online }\end{array}$ & $\begin{array}{c}\text { Moran, José Manuel. Contribuições para uma pedagogia } \\
\text { online. In: SILVA, Marco (Org.). Educação online: } \\
\text { teorias, práticas, legislação, formação corporativa. 4. ed. } \\
\text { São Paulo: Edições Loyola, 2012. cap. 2. p. 41-52. }\end{array}$ \\
\hline Maria Luiza Belloni & $\begin{array}{c}\text { Educação a } \\
\text { distância }\end{array}$ & $\begin{array}{c}\text { Belloni, Maria Luiza. Educação a Distância. Campinas: } \\
\text { Autores Associados, 2006. }\end{array}$ \\
\hline Pierre Lévy & $\begin{array}{c}\text { As tecnologias da } \\
\text { Inteligência: o } \\
\text { Futuro do } \\
\text { Pensamento na Era } \\
\text { da Informática }\end{array}$ & $\begin{array}{c}\text { Lévy, Pierre. As Tecnologias da Inteligência: O Futuro } \\
\text { do Pensamento na Era da Informática. Rio de Janeiro: } \\
\text { 34, 2008. 205 p. Tradução Carlos Irineu da Costa, 1.ed. } \\
1997,15 . \text { reimp., 2008. }\end{array}$ \\
\hline
\end{tabular}

\footnotetext{
${ }^{7}$ http://lattes.cnpq.br/6247875000100774

${ }^{8} \mathrm{http}: / /$ lattes.cnpq.br/8919503255281132

${ }^{9}$ http://lattes.cnpq.br/7485134644744641
} 


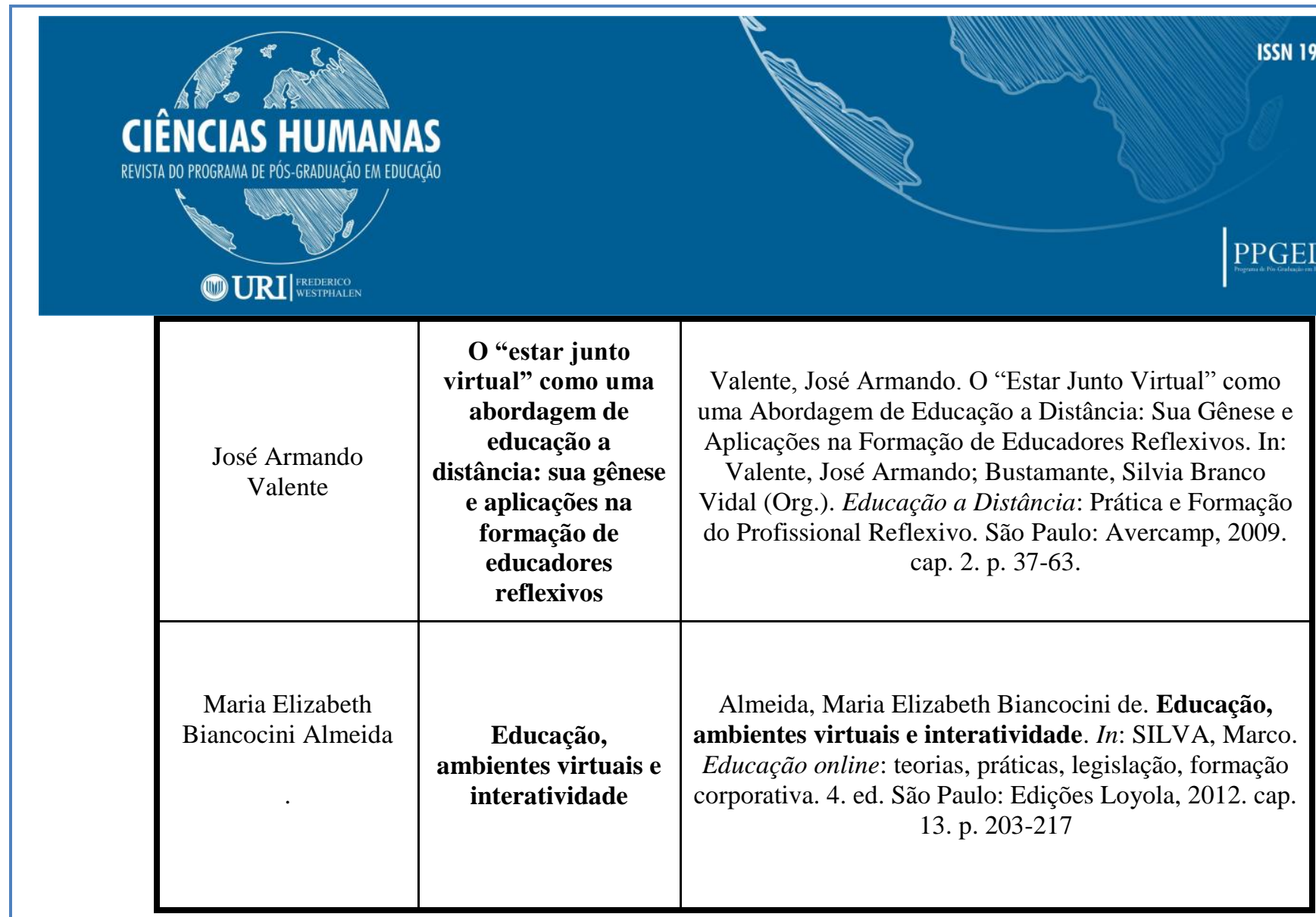

Fonte: Elaborado pelas autoras, 2018.

Além dos autores citados nos artigos analisados, depreende-se do gráfico diferentes interlocutores teóricos distribuídos em 44\%, com 14 autores. Essa diversificação mostra a heterogeneidade teórica dos artigos do ESUD na formação de professores na $\mathrm{EaD}$, podendo se pensar em um campo em construção.

A partir do levantamento das referências mais utilizadas nos artigos, as obras foram lidas na íntegra e delas extraídas unidades de significado relativas à formação de professores no contexto online. A análise destas unidades de significado também codificadas e categorizadas no Atlas TI, permitiu compreender a formação de professores na Educação online e suas especificidades: a interação e a comunicação no ambiente virtual; a tecnologia intelectual e o tempo, apresentadas a seguir.

\section{FORMAÇÃO DE PROFESSORES NO CONTEXTO DA EDUCAÇÃO ONLINE}

Sobre a formação de professores no contexto online, Belloni (2006) aponta para a necessidade da integração das Tecnologias da Informação e Comunicação (TIC) como caminho para que os professores se tornem usuários ativos, críticos e conceptores de materiais para a Educação online desde a formação inicial, estendendo-se a integração à formação continuada. A autora assinala a importância da integração das TIC na formação inicial e continuada de professores, gerando mudanças na educação básica e 


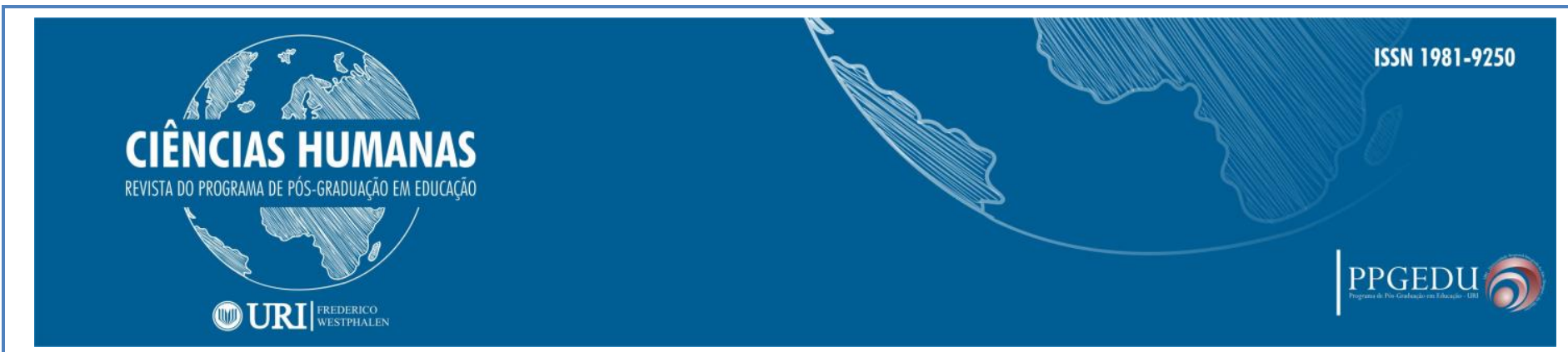

na educação superior, não só para a formação de professores na Educação a Distância, mas para professores atuantes no contexto da Educação online.

Belloni (2006) também argumenta sobre a formação em EaD que, no contexto de formação inicial e continuada, é importante: na formação inicial destacar a aquisição de habilidades de aprendizagem e a interdisciplinaridade, sem descuidar a formação do espírito científico e de competências de pesquisa, e na profissão docente a continuidade da formação.

Além disso, Belloni (2006, p. 64) o conceito de mediatização, em que “[...] mediatizar significa conceber metodologias de ensino e estratégias de utilização de materiais de ensino/aprendizagem, que potencializem ao máximo as possibilidades de aprendizagem autônoma." Assim, a competência de mediatizar "será uma das competências mais importantes e indispensáveis à concepção e realização de qualquer ação de EaD (IBIDEM, p. 62)", ou seja, agrega ao perfil dos professores o fato de não serem centralizadores.

Para Moran (2012, p. 43, grifo do autor), na “[...] Educação online os papéis do professor se multiplicam, diferenciam-se e complementam-se, exigindo uma grande capacidade de adaptação e criatividade diante de novas situações, propostas, atividades.". Tal autor descreve que o professor online deve aprender a trabalhar com os mais variados tipos de tecnologias, conexões de internet, diversos softwares, ou seja, para Moran (2012), os professores precisam se preparar para diversas tecnologias a fim de realizarem múltiplas funções.

No contexto da formação de professores, Almeida (2012), por sua vez, destaca a importância de o professor estar atento ao movimento dos alunos:

\begin{abstract}
O professor acompanha o movimento dos alunos no ambiente virtual e seus respectivos engajamentos nas atividades, analisa as estratégias empregadas na busca de soluções para os problemas encontrados, procura realizar intervenções para desencadear reflexões, críticas, novos questionamentos do aluno e reconstruções de conhecimentos (ALMEIDA, 2012, p. 213).
\end{abstract}

Na concepção da autora, professor, na Educação online, é um docente que não centraliza o ensinar, e, sim, propõe-se a ser aprendente e focar no ensino-aprendizagem. Para a autora, a Educação online é um desafio, não em oposição ao presencial, mas por sua especificidade. Para a autora:

[...] a compreensão da complexidade da EaD implica estabelecer interrelações entre as abordagens que fundamentam tanto a educação presencial como a virtual e, sobretudo, implica reconhecer que mudar o meio pelo qual se desenvolve a educação significa mudar a própria educação. (ALMEIDA, 2012, p. 203).

Argumenta que a conexão entre o presencial e a Educação online, permite a 


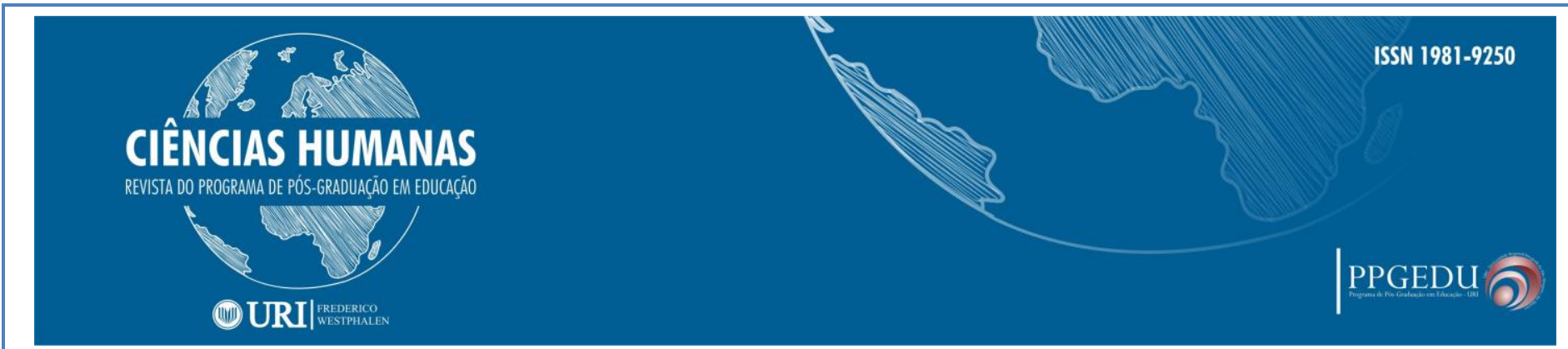

ruptura com as distâncias. Propõe a interação em processos de aprendizagem colaborativos nos ambientes digitais para a construção do conhecimento a partir da elaboração de projetos pedagógicos com o uso das TIC, na busca de alternativas para situações-problemas, vinculando em aprendizagens individuais e coletivas (ALMEIDA, 2012).

Valente (2009) critica que, na Educação online, o presencial é transportado para o online e argumenta que as ações em EaD estão reproduzindo a educação presencial, sem ter um entendimento das diferenças fundamentais entre essas modalidades, principalmente em relação às "[...] contribuições da tecnologia digital ao processo de aprendizagem, à diferença entre informação e conhecimento e o que significa aprender" (IBIDEM, p. 39). Nesse sentido, mostra que é fundamental os professores entenderem que são modalidades diferentes e, assim, a aprendizagem e o ensino precisam ser diferentes em cada modalidade.

Para esses autores ser professor online exige: ser criativo, mediatizador e ter capacidade de inovação.. Esse docente tem uma função no ambiente virtual, planejar as aulas e acompanhar as atividades dos estudantes. É importante que o professor se adeque à Educação online com a apropriação das diferentes tecnologias. O contexto da formação para a Educação online é um desafio a ser enfrentado porque tem que desempenhar múltiplas funções e os professores não se sentem preparados.

Os autores ainda destacam que a formação de professores na modalidade de Educação online apresenta um distanciamento da sala de aula online, o foco é preferencialmente em situações presenciais. Na formação de professores, é pouca a presença de uma formação específica para essa modalidade. Aprende-se a ser professor online ao atuar em cursos nessa modalidade de ensino. É preciso, ao contrário do exposto, ter formações específicas para uso das tecnologias. Entretanto, a interação e comunicação no ambiente virtual são indicadas na formação de professores na modalidade online por ser condição primordial para a atuação nesse espaço de ensinoaprendizagem, de acordo com as seguintes especificidades elencadas nos 'subtítulos a seguir:

\section{Interatividade e Comunicação no Ambiente Virtual}

Interatividade ${ }^{10}$ no ambiente virtual é uma das especificidades apontada como uma característica importante na Educação online e necessária em qualquer modalidade da formação de professores, seja presencial ou a distância. Almeida (2012, p. 210) aponta, em relação aos Ambientes Virtuais de Aprendizagem, que: “[...] este ambiente não é neutro e se modifica à medida que as experiências sociais se desenvolvem e os

\footnotetext{
${ }^{10}$ Assumimos interatividade como "um processo de emissão e recepção como cocriação, com a superação da recepção passiva" (SILVA, 2010, p. 42).
}

\begin{tabular}{l|c|c|c}
\hline Rev. Ciências Humanas & Frederico Westphalen, RS & Pg. 52 - 67 & mai./ago. 2018
\end{tabular}




\section{CIÊNCIAS HUMANAS}

REVISTA DO PROGRAMA DE PÓS-GRADUAÇ̄OA EM EDUCAÇ̄̃O

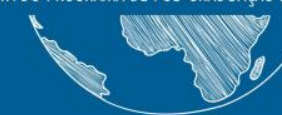

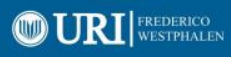

significados são construídos no plano coletivo e individual”. Para a referida autora, interatividade é um espaço de comunicação que permite a cocriação ${ }^{11}$ num ambiente flexível que se transforma pela construção de experiências sociais e significados, individualmente ou coletivamente.

Assim como Almeida (2012), Valente (2009) também apresenta seu conceito de interação: “[...] a abordagem do 'estar junto' incorpora as ideias do ciclo, mas centrados na interação entre os participantes do curso e não só na interação aprendiz-computador (ALMEIDA, p. 53, grifo do autor)." Esse autor indica a interação sem contato presencial, para além da interação somente com o computador, sendo também por todos participantes de um curso. Belloni (2006), com uma leitura semelhante de interação de Valente (2009), também aponta a interação homem-máquina e conceitua interação como ação recíproca entre dois ou mais atores, em que ocorre a intersubjetividade e interatividade como potenciais técnicos para '[...] receber em troca uma 'retroação' da máquina sobre ele (VALENTE, p. 58, grifos da autora)."

O conceito de interatividade para os autores se complementa. Para Almeida (2012), o usuário precisa ser ator e autor, cocriador do conteúdo da comunicação interativa e apresenta interação e interatividade como sinônimas. Para Belloni (2006), interação está no aspecto sociológico, na intersubjetividade da relação entre sujeitos e interatividade na relação com a máquina e os softwares. Moran (2012), por sua vez, aponta a necessidade de uma pedagogia flexível, integradora e experimental.

Apesar de a interação ser através dos computadores e da internet, um ponto em comum entre os autores é essa relação da tecnologia com os sujeitos. Para Almeida (2012), a disposição interativa permite uma interação nos ambientes virtuais e propicia o desenvolvimento coconstruído dos participantes, ou seja, para além da máquina. Valente (2009) enfatiza que a interação não é somente aprendiz-computador. Belloni (2006) apresenta, no aspecto sociológico, a interação e a relação com a máquina como interatividade. E Moran (2012), no contexto educativo, aponta que, mesmo com a evolução tecnológica, para se ter interação, necessita-se de uma pedagogia inovadora.

Um processo de interação destacado pelos autores é a interface ${ }^{12}$ de comunicação instantânea. Moran (2012) incorpora essas interfaces na definição de Educação online: "Pode-se definir educação online como o conjunto de ações de ensino aprendizagem desenvolvidas através de meios telemáticos, como a internet, a videoconferência e a teleconferência" (MORAN, 2012, p. 41).

Belloni (2006, p. 55), argumenta sobre a superação da distância na Educação online, "[...] os problemas gerados pela separação no espaço (descontiguidade) podem ser mais facilmente superados por sistemas eficientes de comunicação pessoal

\footnotetext{
${ }^{11}$ Ao assumirmos (Silva, 2010) nos apropriamos de seus conceitos de cocriação e e coconstruido sem o hífen.

${ }^{12}$ Para Silva (2010, p. 46), "Interface é um termo que, na informática e na cibercultura, ganha o sentido de dispositivo para encontro de duas ou mais faces em atitude comunicacional, dialógica ou polifônica."
}

\begin{tabular}{l|c|c|c}
\hline Rev. Ciências Humanas & Frederico Westphalen, RS & Pg. 52 - 67 & mai./ago. 2018
\end{tabular}

\begin{tabular}{l|l} 
Recebido em: 09/07/2018 & Aceito em: 21/09/2018
\end{tabular}




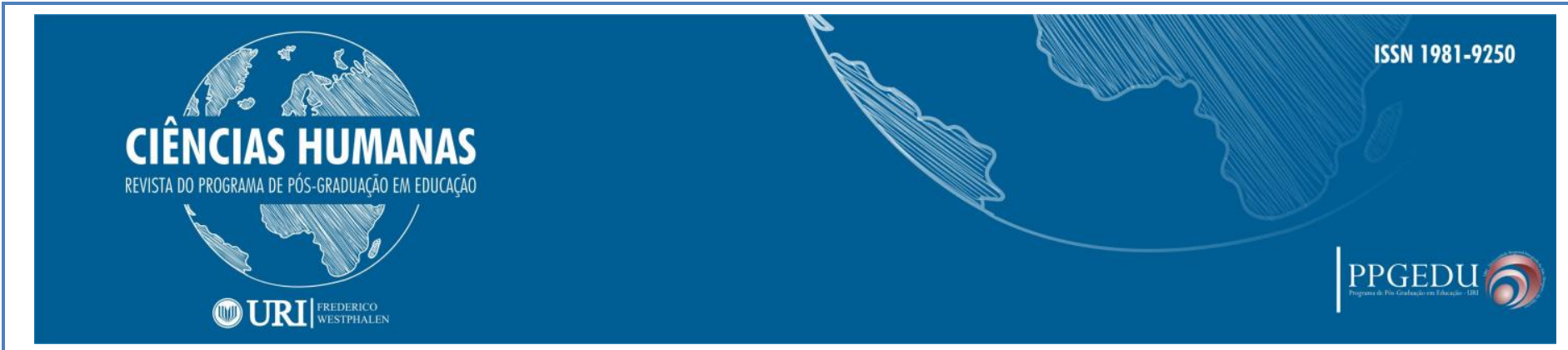

simultânea ou diferida entre os estudantes, tutores e professores e entre os próprios alunos". Almeida (2012, p. 206) critica a comunicação de rádio e televisão, ponto a ponto, por ocorrer em uma única direção, em que "A interação caracteriza-se pela ação de ouvir, ver, ler as informações veiculadas", ou seja, sem interação no sentido de cocriação.

Esses interlocutores teóricos mostram um ponto comum em relação à comunicação: a importância do diálogo na interatividade. A tecnologia pode proporcionar a comunicação humana por áudio, imagem e compartilhamentos diversos, isto é, uma proposição fundamental para a Educação online por proporcionar a interatividade no espaço virtual.

Lévy, apresenta os aspectos sociológicos e filosóficos das tecnologias para comunicação, mencionando que: "Se o assunto em questão é, por exemplo, comunicação verbal, a interação das palavras constrói redes de significação transitórias na mente de um ouvinte" (LÉVY, 2008, p. 23). Ao definir comunicação, o autor aponta "Palavras, frases, letras, sinais ou caretas interpretam, cada um à sua maneira, a rede das mensagens anteriores e tentam influir sobre o significado das mensagens futuras (IBIDEM, 2008, p. 22)."

Comunicar-se coletivamente no ciberespaço propicia criar novos contextos, de modo a construir histórias. Lévy (2008, p. 73) conceitua essa comunicação como hipertexto, uma conexão não linear, anterior às novas mídias, na qual há "um diálogo recursivo em que os textos ecoam mutuamente, extrapolando as fronteiras da linearidade do discurso" “. Essas concepções são indicativas na formação de professores, pois os interlocutores teóricos apontam que a interface de comunicação provoca a interação na Educação online, a contiguidade, a não passividade de um emissor e um receptor e a significação.

Nas obras estudadas, os autores assinalam a interatividade como estabelecimento de comunicação entre professores e estudantes, não somente com o computador e o ambiente de aprendizagem. Para isso acontecer é necessária uma pedagogia inovadora de cocriação. A interação e comunicação estão relacionadas na construção de redes de significados, não linear, mas sim como processo dialógico e de cocriação. A tecnologia, para os autores tem visões diversificadas tanto de como ela pode produzir conhecimento e diálogo, como a necessidade de apropriação e suporte técnico para a utilização pelos professores. Assim, a questão da apropriação e interatividade com a tecnologia intelectual é um dos pressupostos na formação de professores.

\section{Tecnologia Intelectual}

Tecnologia intelectual é também uma das especificidades da Educação online e da formação de professores. Assumimos tecnologia intelectual a partir de Lévy (2008, p.

\begin{tabular}{l|l} 
Recebido em: 09/07/2018 & Aceito em: 21/09/2018
\end{tabular}




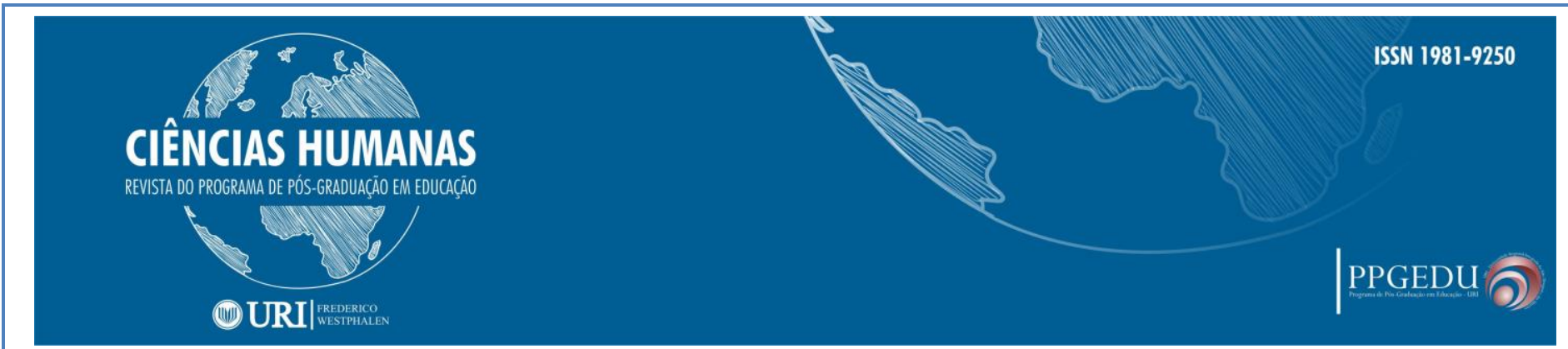

146) em que "Uma tecnologia intelectual deve ser analisada como uma rede de interfaces aberta sobre a possibilidade de novas. conexões e não como uma essência". Essa é a perspectiva na Educação online, operar as tecnologias para aprender, apreender e ir além do que se apresenta na interface dos ambientes virtuais de aprendizagens (AVA).

Nesse sentido, Belloni (2006) apresenta o conceito de tecnologia relacionada à educação por necessitar "[...] de uma reflexão sobre a 'tecnologia' (no sentido do conhecimento embutido no artefato e em seu contexto de produção e utilização)" (BELLONI, 2006, p. 53, grifo da autora). Assim, a tecnologia é para além da máquina, no contexto online a interação pelo professor é indireta. Para ter sucesso, necessita de suporte técnico adequado e da mediatização docente mais do que a educação convencional. Para a autora, a tecnologia se relaciona com a educação na acepção de produção de conhecimento (IBIDEM, 2006) ou seja, tecnologia intelectual.

Para Moran (2012), a inovação na Educação online carece de professores capacitados para o uso de recursos tecnológicos, assim, propõe que seja oferecida essa solução para docentes que têm apropriação da tecnologia, complementando ao argumento de Belloni (2006), que aponta também para a necessidade de suporte tecnológico. A autora complementa, não no sentido de ter conhecimentos técnicos, mas do que emerge no uso das tecnologias, os problemas recorrentes de: conexão, falhas tecnológicas, travamento de programas, incompatibilidade de periféricos, problemas de áudio e vídeo. Estas são algumas dificuldades no uso das tecnologias, aspecto que desmotiva seu uso pelos professores.

Almeida (2012, p. 205) apresenta o papel da tecnologia no estabelecimento de "[...] diálogo entre o indivíduo e o grupo, a virtualidade e a realidade, a razão e a emoção, o analógico e o digital". Nesse sentido, Valente (2009) e Almeida (2012) vão ao encontro dos conceitos de Lévy (2008), em que as tecnologias são da inteligência, ou seja, "[...] que a maior parte dos programas atuais desempenha um papel de tecnologia intelectual: eles reorganizam, de uma forma ou de outra, a visão de mundo de seus usuários e modificam seus reflexos mentais" (LÉVY, 2008, p. 54, grifo do autor). Ele também apresenta a recursividade e a relação com o real: "Ao desfazer e refazer as ecologias cognitivas, as tecnologias intelectuais contribuem para fazer derivar as fundações culturais que comandam nossa apreensão do real” (IBIDEM, p. 10). Para o autor, "A ecologia cognitiva é o estudo das dimensões técnicas e coletivas da cognição" (LÉVY, 2008, p.137, grifo do autor).

Esses autores elencam concepções de tecnologia: artefato técnico e artefato como produção de conhecimento; artefato para a capacitação de professores na Educação online; artefato para a formação no espaço de interação na internet e como uma interface para o diálogo. Unindo essas visões, em Lévy (2008), as tecnologias proporcionam a interatividade, a visão de mundo pela compreensão do real, contextos 


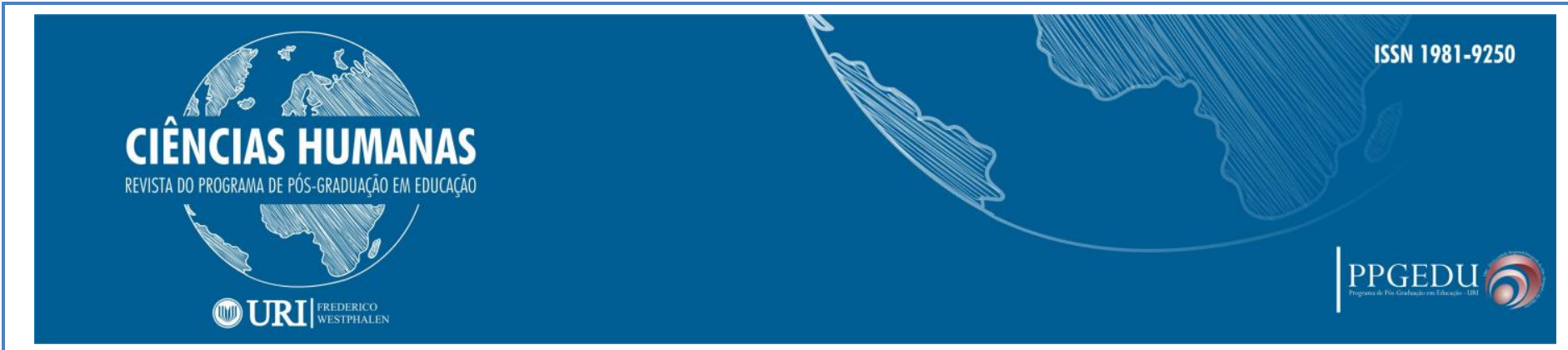

importantes na Educação online. Isso porque essa modalidade apresenta peculiaridades de Tecnologias de Informação e Comunicação, que inverte a lógica da aprendizagem centrada no professor. Portanto, no contexto online a formação de professores é um caminho de construir e reconstruir planejamentos para a Educação nessa modalidade, acessando e se apropriando das tecnologias como artefato de construção do conhecimento.

Outra especificidade da formação na Educação online é o tempo no espaço virtual, discutido a seguir.

\section{Tempo e Espaço na Educação online}

Um conceito apresentado na relação com a tecnologia é o de tempo. Valente (2009, p. 38) assinala que, na Educação online, o tempo deixa de ser empecilho para a interação, em que "O distanciamento temporal passa a significar a possibilidade ou não de realizar atividades simultâneas ou síncronas". Almeida (2012, p. 210) indica o espaço e o tempo no aspecto dialógico do presencial para o virtual, essa proposição, segundo a autora, "permite continuar o diálogo de qualquer outro espaço físico que permita o acesso à Internet e em qualquer momento que se tenha disponível.". Para esses interlocutores, na Educação online, as interações dialógicas são para além da barreira da distância, o tempo apresenta uma dilatação e possibilita a aproximação em momentos síncronos e assíncronos.

Belloni (2006, p. 27) mostra o tempo e o espaço inter-relacionados no binômio professor-estudante na Educação online e aponta que "[...] a separação no tempo comunicação diferida - talvez seja mais importante no processo de ensino e aprendizagem a distância do que a não contiguidade espacial". Além disso, aponta a visão do estudante online, "Do ponto de vista do aluno, pode ser mais fácil 'lidar' com a separação no espaço do que com a dimensão imaterial do tempo" (IBIDEM, p. 55, grifo da autora). A Educação online é uma modalidade de ensino que os estudantes não precisam necessariamente estar no mesmo momento em interação, o espaço virtual é visível e compartilhado, enquanto o tempo nem sempre tem essa concretude da sala de aula presencial.

Moran (2012) distingue o tempo na Educação online pela flexibilidade e contribuindo para o presencial. Conceitua tempo real e tempos diferentes para comunicação e interação: "Denomino a comunicação em tempo real online e online e a de tempos diferentes offline" (IBIDEM, p. 42, grifo do autor). Enquanto isso, Lévy (2008, p. 76) menciona que "Linguagem e técnica contribuem para produzir e modular o tempo". O autor usa o termo "espaço-tempo" como palavra composta e faz relação com a memória social: "Nas sociedades sem escrita, a produção de espaço-tempo está quase totalmente baseada na memória humana associada ao manejo da linguagem"

\begin{tabular}{l|l} 
Recebido em: 09/07/2018 & Aceito em: 21/09/2018
\end{tabular}




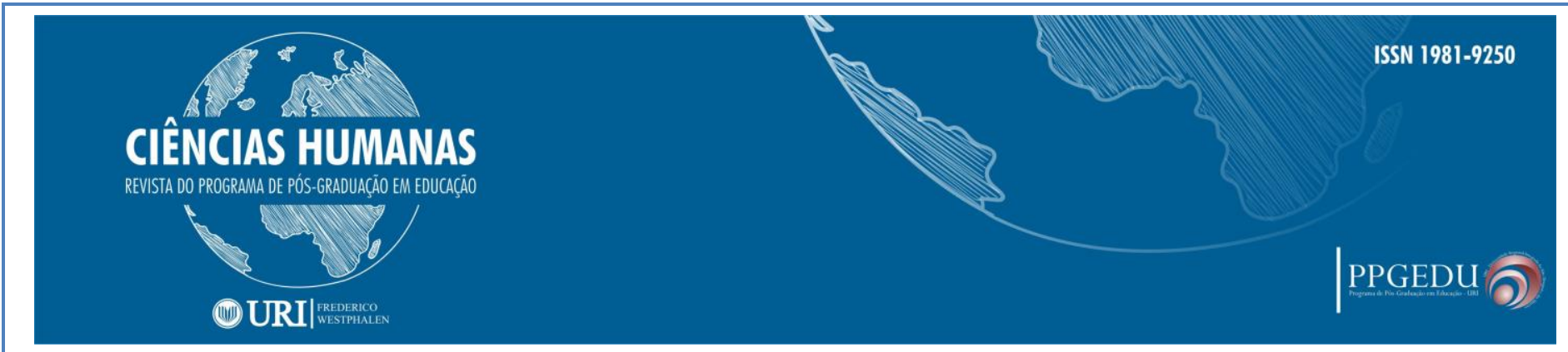

(IBIDEM, p.78). O autor ainda relaciona o tempo e a tecnologia, mas com foco na sociedade que prioriza as tecnologias de comunicação em detrimento da história.

Lévy (2008), diferente dos outros interlocutores teóricos, não aborda o tempo de forma linear, mas como processo tecnológico de compressão e de invenção humana. Ressalta o tempo que, a partir das fases da lua, passou a fazer parte da sociedade primitiva, "Quando uma comunidade de camponeses semeia o campo, está confiando sua vida à terra e ao tempo" (IBIDEM, p. 87). Esse é um modo empírico de se medir o tempo. Explana que, tecnicamente, o tempo e sua medida modificam a história,

\begin{abstract}
Mais profundamente, a técnica toma parte plenamente no transcendental histórico. Para citar apenas este exemplo clássico, sabemos que o espaço e o tempo tal como os percebemos e vivemos hoje na Europa ou na América do Norte não resultam apenas de discursos ou de ideias sobre o tempo e o espaço, mas igualmente de todo um imenso agenciamento técnico que compreende os relógios, as vias de comunicação e transporte, os procedimentos de cartografia e de impressão, etc. (IBIDEM, p. 15).
\end{abstract}

Nesse sentido, o tempo para o autor, é um processo tecnológico. Relacionandose com a Educação online e a formação de professores, pode-se apontar o tempo que, para Lévy (2008, p. 115, grifo do autor) é o tempo pontual, em que "Por analogia com o tempo circular da oralidade primária e o tempo linear das sociedades históricas, poderíamos falar de uma espécie de implosão cronológica, de um tempo pontual instaurado pelas redes de informática”. Para Valente (2009), Belloni (2006) e Moran (2012), o tempo, na formação de professores, está relacionado à interatividade e comunicação síncrona e assíncrona, para Lévy (2008), o tempo pontual é intrínseco à imediatez da informática.

\title{
CONSIDERAÇÕES FINAIS
}

Neste artigo, pretendeu-se identificar as especificidades da Educação online na formação de professores apontados nas obras mais referenciadas dos trabalhos no ESUD, que foram: o contexto online a ser incluído na formação inicial e continuada de professores, a interatividade e a comunicação, a tecnologia intelectual e o tempo e espaço na referida modalidade Educação.

É urgente incluir as tecnologias na formação inicial e continuada de professores por ainda não ser contemplada nos cursos de Licenciaturas. Na formação de professores na Educação online. Sendo a rede de informática promotora da interação no ambiente digital, para além da relação sujeito/ máquina, é a cocriação de aprendizagens dos sujeitos no ambiente a partir da comunicação, do diálogo, de trocas, de associações e de significações. 


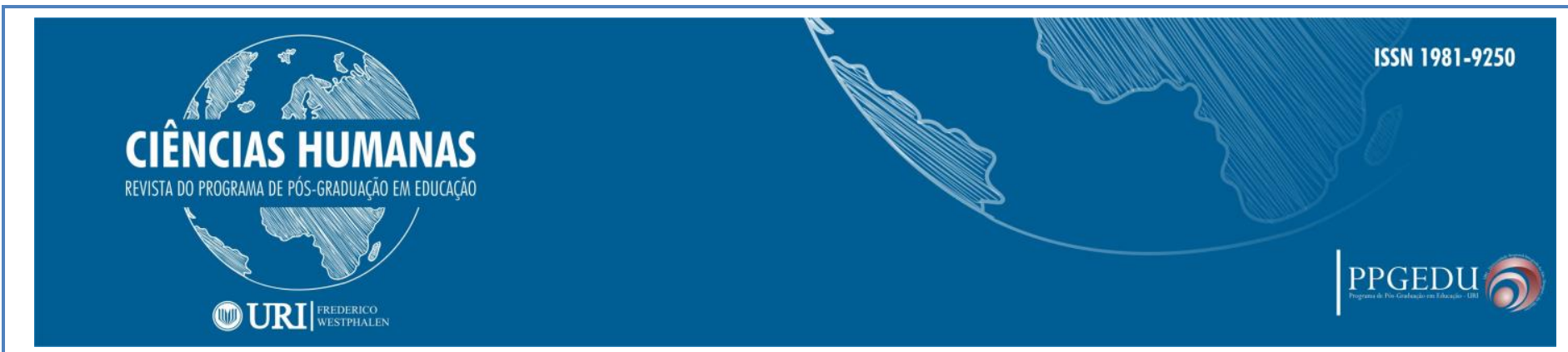

A interatividade é uma especificidade da Educação online para além da apropriação dos matérias disponibilizados nos ambientes virtuais de aprendizagens (AVA). Interatividade é a relação entre sujeitos. As interfaces de comunicação são fundamentais para proporcionar a significação e a interação entre os sujeitos participantes nessa modalidade de Educação online que é feita quase completamente através do AVA.

A tecnologia intelectual, na qual os sujeitos operam a técnica e a máquina como artefatos de construção do conhecimento tem sua especificidade diretamente relacionada ao ambiente virtual e a comunicação. O tempo, na formação de professores e na Educação online, é um fator relevante para o diálogo, seja síncrono ou assíncrono, ou tempo pontual. O tempo na formação presencial é diferente do tempo na $\mathrm{EaD}$, não é mais nem é menos, é outro tempo. É para além do tempo relógio numérico, é o tempo de interação nas interfaces e nas redes de comunicação que produzem aprendizagens.

Os aspectos específicos salientados são pouco explorados nos cursos de licenciatura no presencial e inclusive no EaD. Nesse contexto, são necessárias proposições metodológicas específicas para a Educação online, para não se transferir para o virtual a formação de professores de modo idêntico ao presencial, o que é um equívoco.

Do que foi estudado, o que se compreendeu como especificidade da Educação online foi a necessidade de inclusão urgente do estudo na Educação online nos cursos de formação de professores em qualquer modalidade, seja nos cursos presenciais ou à distância. Uma segunda especificidade tratada como interatividade e comunicação é na sua compreensão da interface como lugar de cocriação de diálogos. Esta especificidade rompe com verticalidades e hierarquias na sala de aula online pois a possibilidade de interação é largamente ampliada e o professor precisa aprender a lidar com esta complexidade.

Pensar que toda a tecnologia tem em si algo que a problematiza na formação de professores na Educação online, pois é preciso entender que a tecnologia diz e diz também pelo que não diz. Ela tem uma intenção intelectual mesmo que o autor não a identifique a tenha percebido.

Por último, a especificidade que se mostrou foi a do tempo considerado pelos autores mais como grandeza física dando importância ao síncrono e assíncrono ou como grandeza ligada ao espaço. Depreendeu-se do estudo a necessidade de compreender mais intensamente o tempo pontual como invenção humana a fim de poder pensar na formação de professores em qualquer de suas modalidades como lugares de abertura de caminhos ainda não percorridos, aproveitando o aprendido, mas deixando tempo para o que ainda não se sabe. 


\section{REFERÊNCIAS}

ALMEIDA, Maria Elizabeth Biancocini de. Educação, ambientes virtuais e interatividade. In: SILVA, Marco. Educação online: teorias, práticas, legislação, formação corporativa. 4. ed. São Paulo: Edições Loyola, 2012. cap. 13. p. 203-217.

BELLONI, Maria Luiza. Educação a Distância. Campinas: Autores Associados, 2006.

FRONTEIRAS DO PENSAMENTO. Pierre Lévy. Porto Alegre: Libreto, 2016.

Pierre. Disponível em:

<http://www.fronteiras.com/ativemanager/uploads/arquivos/produtos_culturais/bd1cef6 02a800e367fb6a3ee5dda847d.pdf>. Acesso em: 21 set. 2018.

LÉVY, Pierre. As Tecnologias da Inteligência: O Futuro do Pensamento na Era da Informática. Rio de Janeiro: 34, 2008. 205 p. Tradução Carlos Irineu da Costa, 1. ed. 1997,15. reimp., 2008.

LÉVY, Pierre. . O ciberespaço como um passo metaevolutivo. Famecos, Porto Alegre, v. 13, n. 6, p.59-67, dez. 2000. Semestral. Disponível em:

<revistaseletronicas.pucrs.br/ojs/index.php/revistafamecos/article/download/.../2357>. Acesso em: 5 set. 2017.

MORAN, José Manuel. Contribuições para uma pedagogia online. In: SILVA, Marco (Org.). Educação online: teorias, práticas, legislação, formação corporativa. 4. ed. São Paulo: Edições Loyola, 2012. cap. 2. p. 41-52.

MORAN, José Manuel. Educação Humanista Inovadora: Quem Sou. [2002]. Disponível em: <http://www2.eca.usp.br/moran/>. Acesso em: 21 jul. 2016

SILVA, Marco. Educar na Cibercultura: Desafios à Formação de Professores para Docência Online. Revista Digital de Tecnologia Cognitivas, São Paulo, n. 3, p.36-51, jun. 2010. Semestral. Disponível em:

<http://www4.pucsp.br/pos/tidd/teccogs/artigos/2010/edicao_3/3-

educar_na_cibercultura-

desafios_formacao_de_professores_para_docencia_em_cursos_online-

marco_silva.pdf>. Acesso em: 2 ago. 2016

SILVA, Marco. Educação online: teorias, práticas, legislação, formação corporativa. São Paulo: Loyola, 2003. 512 p.

UNIREDE - ASSOCIAÇÃO UNIVERSIDADE EM REDE (Brasil). Instituições de Ensino Superior (Org.). Histórico da UNIREDE. 2013. UNIREDE - Associação Universidade em Rede. Histórico escrito por Selma Leite. Disponível em: <http://aunirede.org.br/portal/>. Acesso em: 20 jul. 2016. 


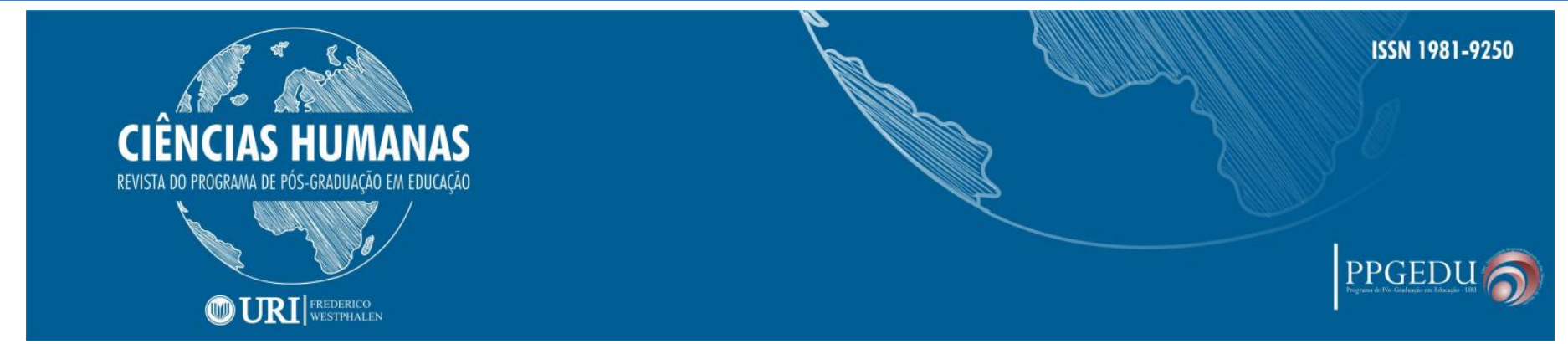

VALENTE, José Armando. O "Estar Junto Virtual" como uma Abordagem de

Educação a Distância: Sua Gênese e Aplicações na Formação de Educadores

Reflexivos. In: VALENTE, José Armando; BUSTAMANTE, Silvia Branco Vidal

(Org.). Educação a Distância: Prática e Formação do Profissional Reflexivo. São Paulo:

Avercamp, 2009. cap. 2. p. 37-63. 